\title{
Changes in Social Communication as a Tool of Social Work under the Influence of Digitalization
}

\author{
OLHA MITCHUK ${ }^{1}$, INNA PENCHUK ${ }^{2}$, NATALIIA PODLUZHNA ${ }^{3}$, OLENA MALOVICHKO ${ }^{4}$, \\ OLGA SHIROBOKOVA ${ }^{5}$, ANGELINA TREGUB ${ }^{6}$ \\ ${ }^{1}$ Department of Social Communications, INTERNATIONAL UNIVERSITY OF ECONOMICS AND HUMANITIES \\ ACADEMICIAN STEPAN DEMIANCHUK, UKRAINE \\ ${ }^{2}$ Department of Journalism and Ukrainian Philology, CLASSIC PRIVATE UNIVERSITY, UKRAINE \\ ${ }^{3}$ Department of Economics, ACCOUNTING AND TAXATION, DONETSK NATIONAL TECHNICAL UNIVERSITY, \\ UKRAINE \\ ${ }^{4}$ Department of Social Philosophy and Management, ZAPORIZHZHYA NATIONAL UNIVERSITY, UKRAINE. \\ E-mail: mal_02@ukr.net \\ ${ }^{5}$ Department of Social Philosophy and Management, ZAPORIZHZHYA NATIONAL UNIVERSITY, UKRAINE \\ ${ }^{6}$ Department of Journalism and Ukrainian Philology, CLASSIC PRIVATE UNIVERSITY, UKRAINE
}

\begin{abstract}
Modern society is a complex multilevel system in which many people coexist with their values and problems. And not all contemporary society members can adapt to its many rules, so sometimes people find themselves outside the community and need the help of social services. The study aims to improve social work tools as an element of social communication under the influence of digitalization. As the research has shown, changing conditions of reality make their adjustments to all aspects of society, including social work tools: they should be modern, relevant, effective, promising and long-term. The COVID-19 pandemic has highlighted society's challenges and social work to help people overcome personal and social hardships more than ever. To do this, the authors studied the features and tools of social work, analyzed social communication through social work prism, and suggested ways to improve social work. Thus, the authors proposed the Algorithm for enhancing the organization and conduct of social work through social communications and a methodology for calculating the effectiveness of social work, which are convenient to implement digitally. The developed measures will significantly improve the organization and conduct of social work.
\end{abstract}

Keywords: Human Behaviour, Social Communications, Social Work, Digitalization.

JEL Classification: A13, B55, C31, D91 


\section{Introduction.}

The essential component of social interaction is social communication. A vital characteristic of any communication process is the participants' intention to influence each other. Modern social communications are universal, comprehensive and expansive (Mahanta \& Ali, 2018; Mason \& Bay, 2020). The communicative space at different levels becomes fluid, variegated and complicated due to the overwhelming scale and globality of socio-communicative processes. Simultaneously, the growing communication flows testify to the previously unknown availability and freedom of information, autonomy in the creation of individual and collective experience, openness and independence in everyday practices. In other words, the modern world is woven from a mass of contradictions of socio-communicative development (Bowles et al, 2020). It can be called the paradox of communicative freedom. The cost of expanding the public, both professional and everyday field of social communications, is the loss of the communicative independence of the individual. As a communicative personality, he turns into a personal reflection of more diverse and refined methods of informational influence of many channels and forms of communication, including digital.

A special place in social communications is occupied by the question of the growing need for social work tools for socio-cultural orientation towards the audience, the construction and translation of meanings in various forms: verbal, non-verbal, visual, discursive. They constitute the core of socio-communicative practices, which are forming, consolidating and routinizing the methods of communicative knowledge, skills, abilities and actions in the interests of the participants in the interaction.

\section{Social work.}

Social work - a field of scientific knowledge, academic discipline and professional activity aimed at maintaining and providing qualified assistance to any person, group of people, community, which expands or restores their ability to social functioning, promotes civil rights, prevents social exclusion (Semigina \& Mygovych, 2005).

Social work as a professional activity is an interconnected system of values, theory, and practice. Its mission is to allow people to develop their full potential, enrich their lives and prevent dysfunction (Bondarenko et al, 2004).

It is a system of theoretical knowledge and practice based on them, which aims to ensure social justice by encouraging and supporting the most vulnerable sections of society and counteracting social exclusion factors (Poltavets, 2020).

Social work is a practical activity that happens in a complex, changing environment. It is designed to allow people to develop their full potential, enrich their lives and prevent dysfunction. Using human behavior and social systems theories, social work occurs where people interact with their environment. Social work builds its methodology on "evidence-based" knowledge gained from research and evaluation of social work practice, including specific knowledge about their context (Semigina \& Bryzhovata, 2002).

As follows from the definition of social work adopted by the International Association of Schools of Social Work and the International Federation of Social Workers on June 27, 2001, in Copenhagen, "the professional activity of social workers contributes to social change, solving problems of human relations; promotes the strengthening of the capacity for functional existence in society and the liberation of people to increase their level of well-being. Using human behaviour and social systems theories, social work facilitates the interaction of people with their environment. The principles of human rights and social justice are the foundation of social work (Global definition of social work).

Thus, social work can be viewed in three directions (Lasswell, 1948):

as a type of social activity aimed at harmonizing personal and social relations by assisting individuals, groups of people and communities experiencing difficulties in social functioning, through 
protection, support, correction and rehabilitation, as well as by changing and reforming individual elements of the social system;

as a theory that studies the ways and methods of the impact of social adaptation and the implementation of the subjectivity of the individual and the group by social norms and values of the society in different space-time situations;

as an academic discipline of a multilevel nature, taught in secondary specialized and higher educational institutions and the system of advanced training for workers in the social sphere. Such a multifaceted modern interpretation of social work as a professional activity, the theory of scientific knowledge of contemporary society and academic discipline represent it as a unique social phenomenon. Social work is currently one of the most critical humanitarian professions necessary for the sustainable social development of society.

The subject of social work is not all social relations. Still, a group of connections that are the most problematic, that is, lead to destabilization, social disorganization, an increase in social tension, the emergence of social conflicts, people getting into difficult life situations; as well as patterns of interaction between subjects of social work when optimizing social relations (in the process of forming the ability to restore a social subject). Social work studies activity, that is, the introduction of an active issue into the subject of social work. Social work has several patterns and features (Fig. 1).

By itself, theoretical knowledge of patterns does not yet guarantee their systematic use in social work specialists' daily practice. Patterns are just some guidelines that a social work specialist should know. Therefore, in practice, a social worker most often proceeds from the typicality of clients' problems, uses, first of all, those conclusions and rules that are formulated by science and practice based on open patterns.

Social work principles are essential building blocks of logical forms of scientific theory and the fundamental rules of empirical action.

\section{Social communication through the lens of social work.}

The most crucial component of social interaction is social communication. Although interaction without communication is possible in some situations, in the overwhelming majority of cases, social contacts include communication.

Communication is a mutual exchange of information, implying both participants' orientation to the reciprocal openness of the partner (Prokopenko \& Omelyanenko, 2018). Such exchange occurs not necessarily in a verbal form (verbal), but also in a non-verbal one. Non-verbal communication is much older than verbal communication. It includes gestures and facial expressions, dance, music, visual arts, sculpture and architecture. In fact, the engineering structures, temples, palaces, sculptures, paintings left over from the past centuries convey information without words about the life, feelings, relationships of long-dead people.

As follows from the definition, the essence of the communication process is to transfer a message containing information to another participant. The very act of revealing the content of one's consciousness during communication in sociology is called a signal.

But a signal is not always a message or information. For example, if on the street a social worker turns to a person in a foreign language that he does not know, then the person will receive such a signal but will not receive a real message. Of course, in this case, neither communication nor obtaining information will take place. If something is said that is already known, the person receives the message, but it is not information for him. The message will be information only if it contains something unknown to the person.

The transmission of information in the course of the communicative process requires certain media - symbols and signs since communication by its nature is a symbolic process. Objects that reveal the meaning that they contain not by themselves, but since society has endowed them with 
this meaning, act as symbols and signs. It is the meaning of the sign. Therefore, we can say that communication is the process of decoding signs and reading their social implications.

Figure 1. Specific features of social work

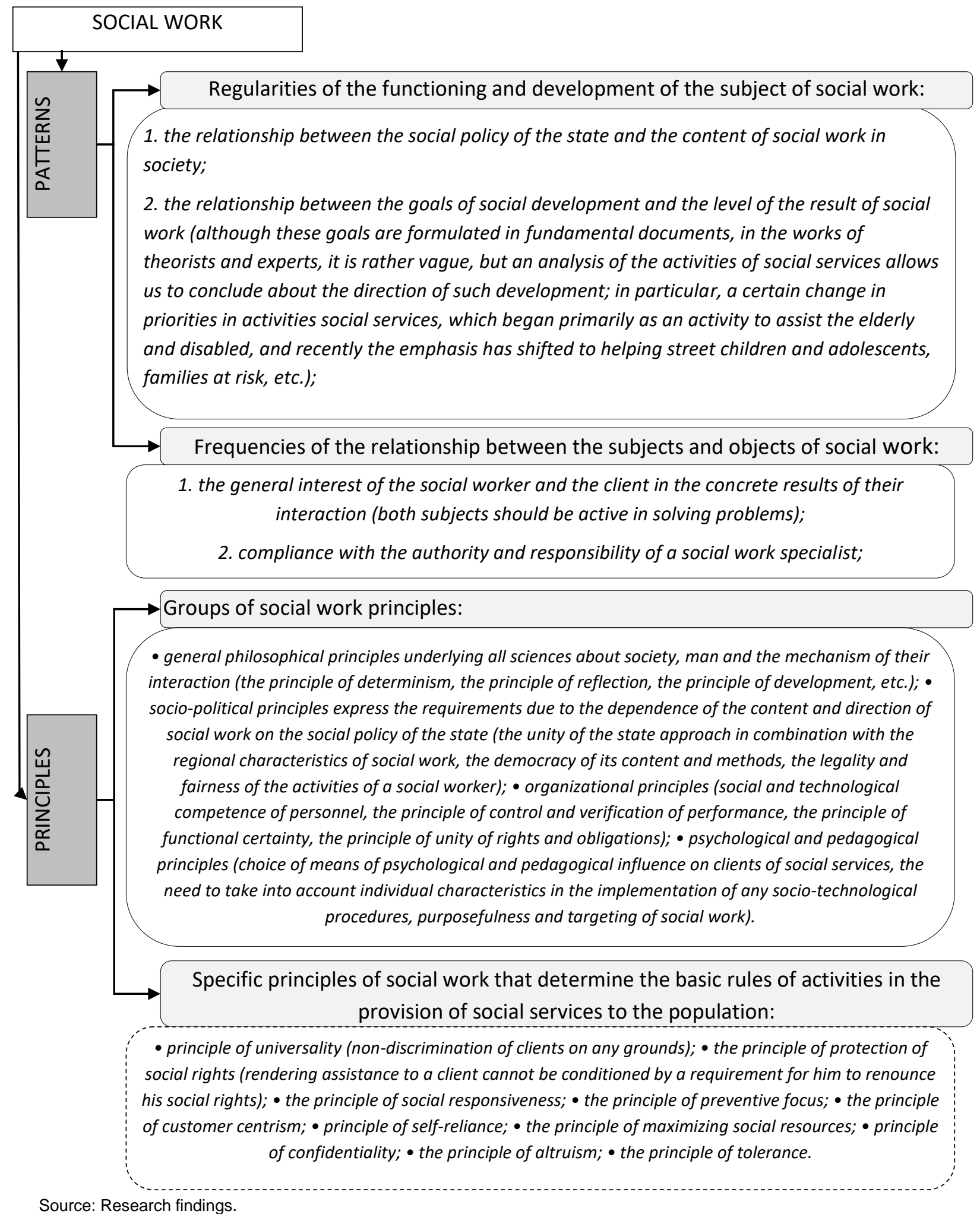

Communication can occur at several levels - between individuals, between social groups, within the same society, or between societies (Dreachslin et al, 2012; Humphreys \& Campbell, 2010). Therefore, the following types of social communication are distinguished:

- by the nature of the target audience - interpersonal, group and mass; 
- by author, source of the message - official and unofficial;

- by way of broadcasting - verbal and non-verbal.

Scientists believe that the formation of a modern information society (a society in which science, knowledge and information play the leading role) was the result of several communication revolutions that changed not only the methods of processing and transmitting data, but also the value system, people's way of life, and the way of production. Revolutions in social communication history were associated with the emergence of writing, typography and electronic devices.

The essence of the social communication process is transferring a message containing information from one communication participant to another participant (Fig. 2).

Figure 2. Lasswell's communication model (Lasswell, 1948)

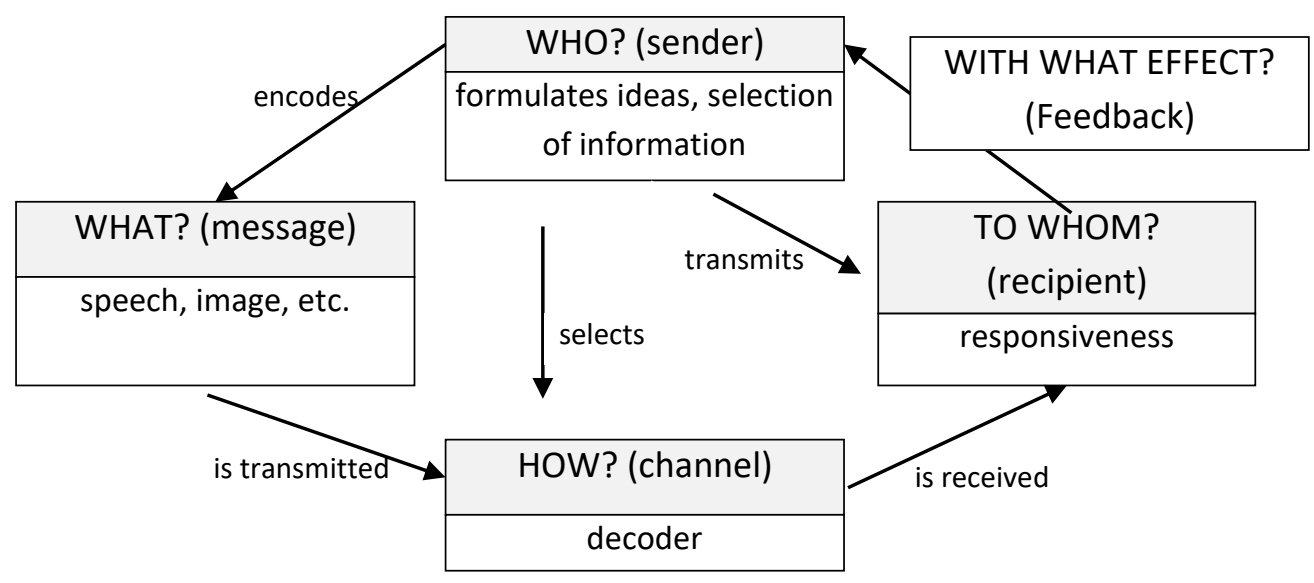

Source: Research findings.

The main media of communication are the press, television, radio, advertising, and the Internet. Television occupies a leading position among the mass media, and its influence is growing every year (Bühring, 2020; Greengrass, 2019; Sinclair, 2020). The results of a study conducted by the Institute of Sociology of the Academy of Sciences (2007) and the authors (2019) demonstrate that the priorities in the system of ways of spending free time among representatives of different generations change over time (Fig. 3).

Since the early 1930s., mass communication came to be seen as a social problem, and before this milestone, the only role of the press was to supply society with information. Due to the rapid development of cinematography and then television, interest in mass media and its possibilities in such areas as political propaganda and education have sharply increased. These opportunities raise concerns in the intelligence community that the mass media's overwhelming influence on the population could have harmful cultural and social consequences. In the United States, similar concerns and apprehension led to the creation, in the 1960s., a select branch of social science that studies the mass media. Note that the study of mass media is fraught with several difficulties, the main one being to separate the scientific approach from the journalistic one. It testifies to the ambiguity of the concept of "mass", which is now more often used in a normative sense (masses are easily deceived and manipulated) than merely in quantitative terms (masses are numerous groups of people). Therefore, social sciences tend to abstract from the second meaning of the concept of "mass". 
Figure 3. Free time and leisure of young people (20-39) and generation of "fathers" (40-60 years old), in 2007 and $2019, \%$

ص2007 20-40 years old $\quad 200740-60$ years old $\quad 201920-40$ years old $\quad 2019$ 40-60 years old

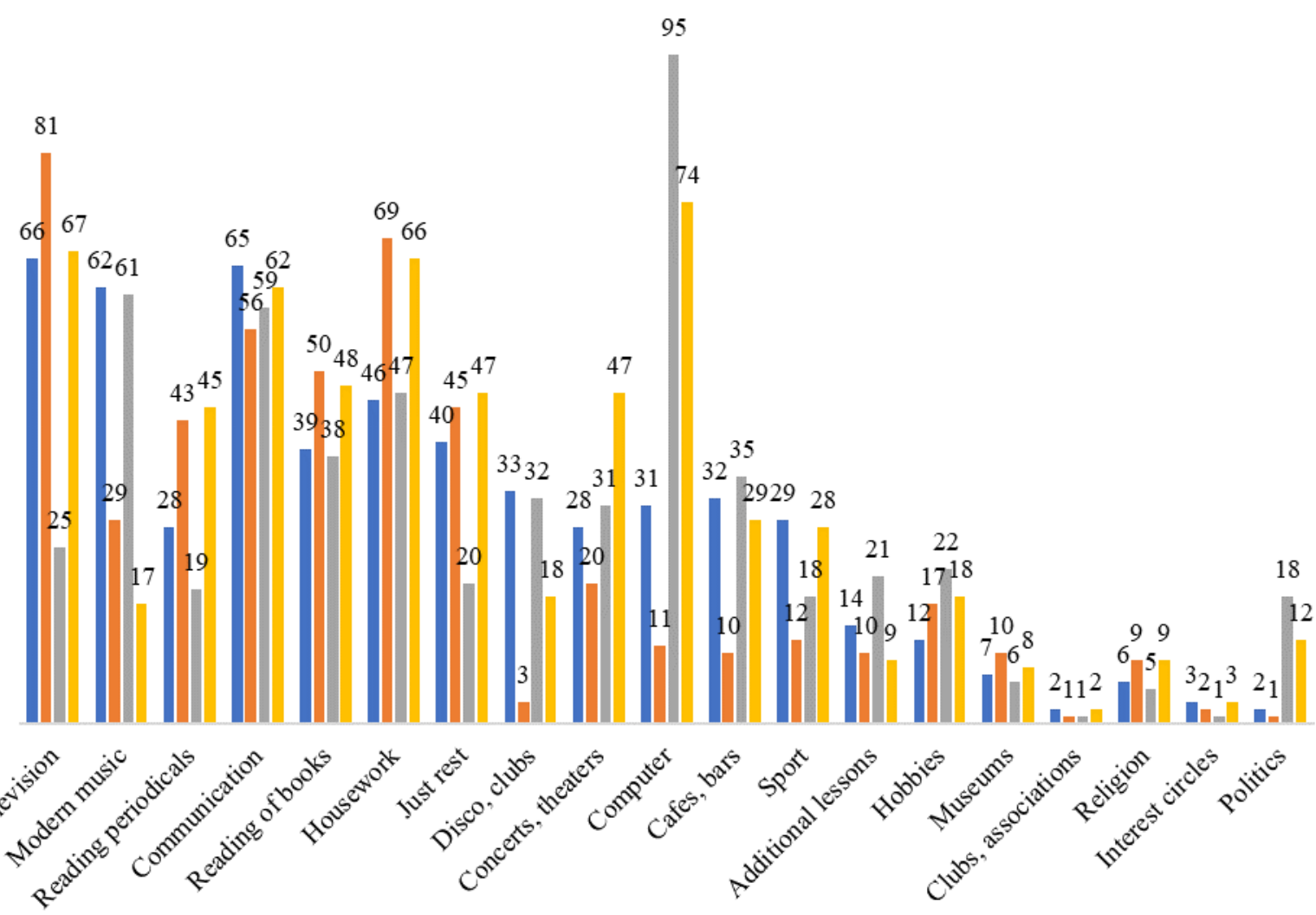

Source: Research findings.

\section{Results: Improving the organization and conduct of social work through social communications.}

Mastering any professional or everyday situation requires cognitive readiness, knowledge, algorithms of actions, anticipation, accounting and understanding of the consequences. The semantic component of intellectual, emotional, volitional and physical activity is the basis of human behavior. The meaningful construction of reality is carried out socio-communicatively, primarily due to various forms of structuring social action. In general, it is necessary to highlight such mechanisms of sociocommunicative construction as meaning, symbolization, idealization, constitution, rationalization, referring to another and some others.

These mechanisms are institutionalized and become a natural resource for reproducing the social structure, cultural differentiation, and personal uniqueness. Actually, these mechanisms operate in all spheres without exception: economics, politics, law, art, etc. In modern societies, many sociocommunicative means of recreation, design, renewal of local socio-cultural communities have been formed, respectively, and at the macro-level - regional, global, world communities. It is in this vein that social work should be directed.

As the study has shown, changing conditions of reality make their own adjustments to all aspects of society, including social work tools: they should be modern, relevant, effective, promising and long-term. The COVID-19 pandemic has highlighted society's challenges and social work to help people overcome personal and social hardships more than ever (Dudić et al, 2020).

To manage the development of social work is necessary to professionally assess the effectiveness of social services provided by social services and other types of social support implemented in the practice of social work. A reliable toolkit for measuring the effectiveness of social services and 
individual social workers' activities is needed; reliable scientifically based criteria and performance indicators are needed, based on which the effectiveness and quality of social work can be measured suitably.

Based on the research, we propose an algorithm for improving social work (Fig. 4).

The use of social communications in the first two stages is most fully disclosed - this is the promotion of social work - so that as many people as possible are aware of its work, services, possible help, and the search for potential people who need help.

Based on the results of monitoring, two-level decisions are made:

- $\quad$ strategic (making proposals for improving legislation, making a forecast of financial support for targeted territorial programs, adjusting and updating the organizational structure of management);

- tactical (drawing up and adjusting plans, providing methodological assistance, organization of information and reference work).

Thus, it can be argued that informatization, technologization, and automation of monitoring, expanding, and optimizing the range of management tasks significantly improve the social service system's key performance indicators.

The final stage of the Algorithm is to evaluate the effectiveness of the social work carried out, and that means the service (Jašková, 2019). In the Algorithm, we indicated that it could be of two types. We will consider each in more detail:

Figure 4. Algorithm for improving the organization and conduct of social work through social communications

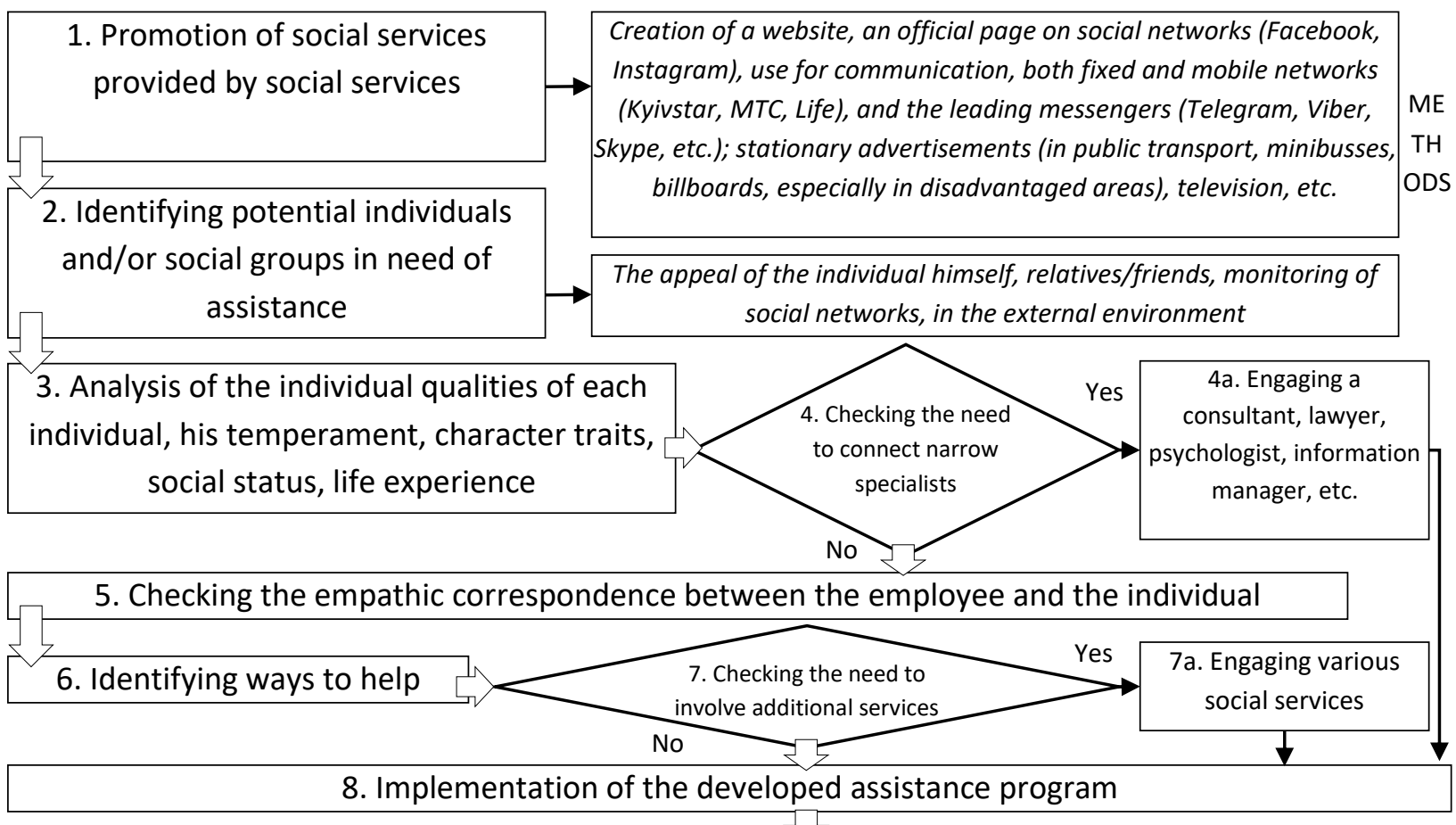

9. Evaluating the effectiveness and/or efficiency of eliminating social, moral, personal, environmental problems

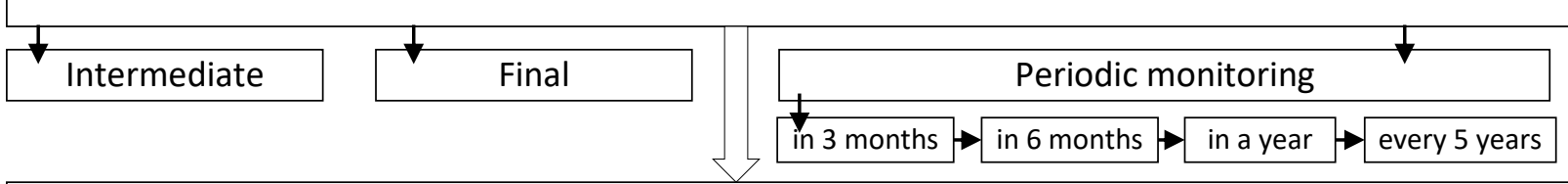

9. Evaluating the effectiveness and/or efficiency of social work

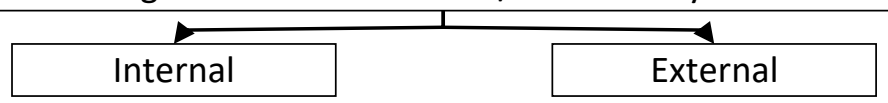

Source: Research findings. 
Internal:

- its coherence, prevention of violations of the law, coverage of services of various categories of citizens, identification of the best institutions, etc.

External:

- the cost of the system (the ratio of funds allocated by the state for social support to the cost of maintaining the system),

- actual receipt of funds by the addressee (the ratio of the number of funds allocated for support to the real number of recipients),

- bringing low-income families to a living wage (the ratio of the total number of citizens who received state social assistance to the total number of low-income families recorded by statistics bodies),

- rehabilitation (labour, social) of citizens who find themselves in a difficult life situation,

- hospital-replacing technologies (the ratio of the number of identified citizens who have partially or completely lost the ability to self-service, but are supported by social service institutions, to the number of people placed in inpatient social service institutions),

- $\quad$ lacement of orphans and children left without parental care in families, provision of an accessible environment for the disabled and the elderly (the total number of facilities to be equipped with technological products that facilitate the accessibility of the environment).

For a quantitative assessment, we suggest using a scale of points:

3.1-4 points - the target, i.e. the result to be achieved;

2.1-3 points - an indicator of the norm (equal to the best indicator of the region or deviation from the target by no more than $10 \%$ );

$1,1-2$ points - the result is assessed, the value of which is $11-25 \%$ lower than the target;

0.1-1 point - a value that is $26-50 \%$ or more below the target;

0 points - a value that is more than $50 \%$ below the target;

After evaluating each criterion in points, each criterion's efficiency coefficient (Cef) is determined, which is calculated as the ratio of the result to the target. Overall efficiency (Coeff) is calculated as the total result ratio to the total target.

For a qualitative assessment of the result obtained, the boundaries of the identified points are determined:

Low efficiency: coefficient up to 0.4 ;

Average efficiency: 0.4 to 0.69

Normal efficiency: 0.70-0.84.

High efficiency: 0.85 to 1.

Approbation of the methodology in 2 centres of social services (Zaporizhzhia - Department of Social Protection of the Population of the Zaporizkoy Ministry for the sake of Shevchenkivsky District; and Rivne - Department of Social Protection of the Population of the Viconary Institution, which is the work of the more effective (normal efficiency), but there are bottlenecks that need improvement (Table 1; Fig. 5).

In Fig. 5 especially clearly shows which indicators should be improved. It is worth noting that it is necessary to analyze each indicator and take measures that can only work in this centre. So, for example, you can suggest:

1. Create a call centre as an opportunity for people without Internet access to get the necessary advice by phone. 
2. When selecting personnel, take into account the specifics of institutions of this kind and prevent inexperienced people from working with people, heads of departments should clearly define the role and place of each employee, avoiding conflicts within the working team.

\section{Conclusion.}

Social work is one of the mechanisms for implementing the social state policy, since its empiricism proceeds from the need to solve specific socio-economic and legal problems of people who find themselves in difficult life situations. Global digitalization and the acceleration of the pace of life significantly increase the social and psychological pressure on various segments of the population. The global COVID-19 pandemic has further exacerbated society's problems. However, global trends can take social work to a new level, provided that social communications are effectively used. Efficiency is an indicator of how the system can, with the available resources, achieve the set goal defined by its functions. In the case of the social protection system, how much it helps to reduce social risks.

Table 1. Comprehensive criteria-based assessment of efficiency for 2019

\begin{tabular}{|l|c|c|c|c|c|}
\hline \multicolumn{1}{|c}{ Criterion } & Target & Zaporizhzhia & \multicolumn{3}{c|}{ Rivne } \\
\cline { 4 - 6 } & reference & Result & $\boldsymbol{C}_{\text {ef }}$ & Result & $\boldsymbol{C}_{\text {ef }}$ \\
\cline { 4 - 6 } & $\mathbf{1}$ & $\mathbf{2}$ & $\mathbf{2} \div \mathbf{1}$ & $\mathbf{3}$ & $\mathbf{3} \div \mathbf{1}$ \\
\hline $\begin{array}{l}\text { 1. Availability of a website, an official page on social } \\
\text { networks }\end{array}$ & 4,00 & 3,80 & 0,95 & 3,50 & 0,88 \\
\hline 2. Activity & 4,00 & 3,70 & 0,93 & 3,20 & 0,80 \\
\hline 3. Number of the population served & 4,00 & 2,70 & 0,68 & 3,40 & 0,85 \\
\hline 4. Availability of queues & 4,00 & 3,20 & 0,80 & 2,90 & 0,73 \\
\hline 5. The range of served categories of the population & 4,00 & 4,00 & 1,00 & 4,00 & 1,00 \\
\hline $\begin{array}{l}\text { 6. Awareness of the people about the services } \\
\text { provided }\end{array}$ & 4,00 & 2,80 & 0,70 & 2,90 & 0,73 \\
\hline 7. Qualification of specialists & 4,00 & 3,40 & 0,85 & 3,30 & 0,83 \\
\hline 8. Satisfaction of employees with working conditions & 4,00 & 3,10 & 0,78 & 2,90 & 0,73 \\
\hline 9. The presence of crises & 4,00 & 2,80 & 0,70 & 2,90 & 0,73 \\
\hline 10. Form of distribution of tasks among employees & 4,00 & 3,30 & 0,83 & 3,40 & 0,85 \\
\hline 11. Team atmosphere & 4,00 & 3,80 & 0,95 & 3,10 & 0,78 \\
\hline 12. Staff turnover & 4,00 & 3,90 & 0,98 & 3,20 & 0,80 \\
\hline 13. Incentive system & 4,00 & 3,10 & 0,78 & 3,00 & 0,75 \\
\hline Total indicators & 52,00 & 43,60 & 0,84 & 41,70 & 0,80 \\
\hline
\end{tabular}

Source: Research findings.

The authors have developed proposals for improving the organization and conduct of social work using social communications, which will rationalize both external and internal information flows, more clearly define the responsibilities of performers and managers, and also ensure the achievement of the maximum level of quality of social services, increasing the level of its availability among the population. 
Figure 5. Comparative assessment of the effectiveness of the Social Protection Departments of Zaporizhzhia and Rivne for 2019

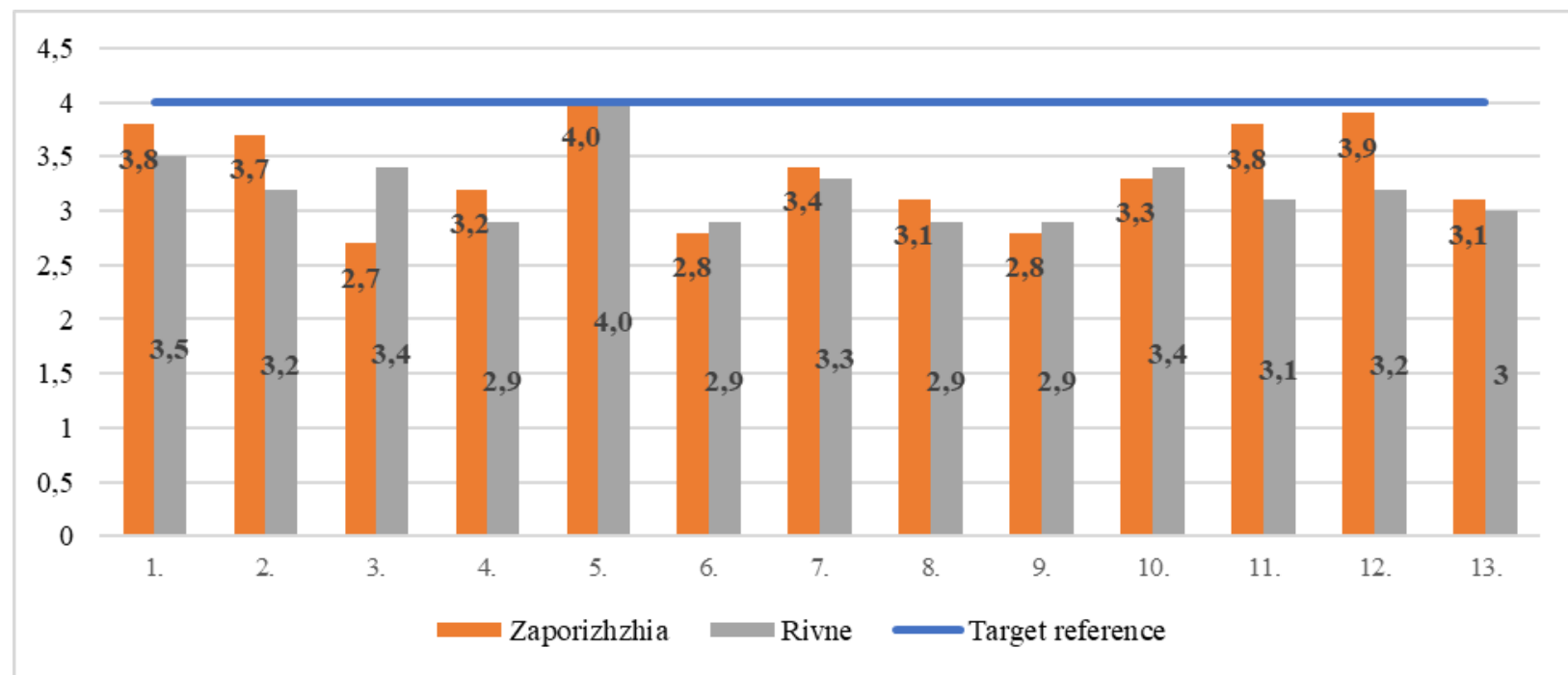

Source: Research findings.

\section{References}

1. Bondarenko, N. et al. (2004). Part 1: Fundamentals of Social Work, In book: Social work: In 3 parts, Kyiv: Kyiv-Mohyla Academy Publishing House, ISBN 966-518-294-3.

2. Bowles, W. et al. (2020). Social work in its environment, In book: Ethical practice in social work, DOI: 10.4324/9781003115526-2

3. Bühring, L. (2020). Aging, Media, and Communication, DOI: 10.1002/9781119429128.iegmc135

4. Dreachslin, J., Gilbert, M., \& Malone, B. (2012). Diversity and Cultural Competence in Health Care: A Systems Approach. John Wiley \& Sons, 480 p.

5. Dudić, Z., Dudić, B., \& Agbaba, B. (2020). Analysis of the European Social Charter and its importance for the protection of selected groups of working women. Central European Journal of Labour Law and Personnel Management, 3(1), pp. 7-20. http://doi.org/10.33382/cejllpm.2020.04.01

6. Global definition of social work. https://www.ifsw.org/what-is-social-work/global-definition-ofsocial-work/

7. Greengrass, M. (2019). Media and communication. In book: Interpreting Early Modern Europe, DOI: $10.4324 / 9780429324574-7$

8. Humphreys, J., \& Campbell, J. (2010). Family Violence and Nursing Practice, Second Edition. Springer Publishing Company, $482 \mathrm{p}$.

9. Jašková, D. (2019). Assessment of social development in Slovakia in the context of human resources. Central European Journal of Labour Law and Personnel Management, 2 (2), 21-32. http://doi.org/10.33382/cejllpm.2019.03.02

10.Lasswell, H. (1948). The Structure and Function of Communication in Society. The Communication of Ideas, New York: Institute for Religious and Social Studies, $117 \mathrm{p}$.

11.Mahanta, P., \& Ali, A. (2018). Psychiatric Social Work Intervention in Person with Schizophrenia Having Poor Social, Communication and Work Functioning. Indian Journal of Psychiatric Social Work, 9(1), 47-53. DOI:10.29120/IJPSW.2018.v9.i1.46

12.Mason, R., \& Bay, U. (2020). Social Work Practice with Communities, In book: Practice Skills in Social Work \& Welfare, DOI: 10.4324/9781003116806-6

13.Poltavets, V. (2020). Social work in Ukraine: the first steps, Kyiv: KM Academia, p. 5. 
14.Prokopenko, O., \& Omelyanenko, V. (2018). Marketing aspect of the innovation communications development. Innovative Marketing, 14(2), pp. 41-49.

15.Semigina, T., \& Bryzhovata, O. (2002). International definition of social work. Social policy and social work, № 3, 4, pp.144-145.

16.Semigina, T., \& Mygovych, I.(2005). Introduction to social work: A textbook for students of higher educational institutions, Kyiv: Academvydav, $300 \mathrm{p}$.

17.Sinclair, J. (2020). The Media and Communications: Theoretical Traditions. In book: The Media \& Communications in Australia, DOI: 10.4324/9781003118084-3 